\title{
Images
}

\section{Ocular Chlamydia Trachoma}

\author{
Naomi George, MD*; Adam C. Levine, MD, MPH* \\ Keywords: Ocular, Chlamydia, Trachoma, International
}

\section{CASE REPORT}

A five-year-old female Sudanese refugee presented to our clinic for evaluation of her left eye. Her father reported worsening of vision over the past two years. On examination, the left eye showed corneal opacity with blurring of the pupillary margin (Figure 1). Distortion of the tarsal conjunctiva was noted, resulting in entropion and redirection of the lower lashes inward (arrow). The patient was diagnosed with trachoma.

Trachoma is the leading cause of infectious blindness worldwide. ${ }^{1}$ Trachoma is endemic in parts of Africa, the Middle East, and India. The disease is particularly problematic in certain regions of Ethiopia and Sudan, where up to $50 \%$ of children have active trachoma. ${ }^{2}$ The causative organism, Chlamydia trachomatis, is spread through direct or indirect contact with eye discharge of an infected person. Children in endemic areas often suffer multiple episodes of infection, leading to chronic follicular conjunctivitis that sets off a cascade of events including conjunctival scarring, entropion, trichiasis, and corneal abrasion. ${ }^{3}$ If untreated, this condition leads to the formation of irreversible corneal opacities and blindness.

The differential diagnosis includes viral and bacterial causes of conjunctivitis, as well as involutional changes-rare in trachoma-endemic regions. Treatment is with oral azithromycin, topical tetracycline, and corrective surgery for inturned eyelashes. Depending on local prevalence rates, treatment is targeted towards the individual patient, or towards the population as a whole. The "SAFE" acronym was developed by the World Health Organization to guide international efforts at prevention and treatment: Surgery for inturned

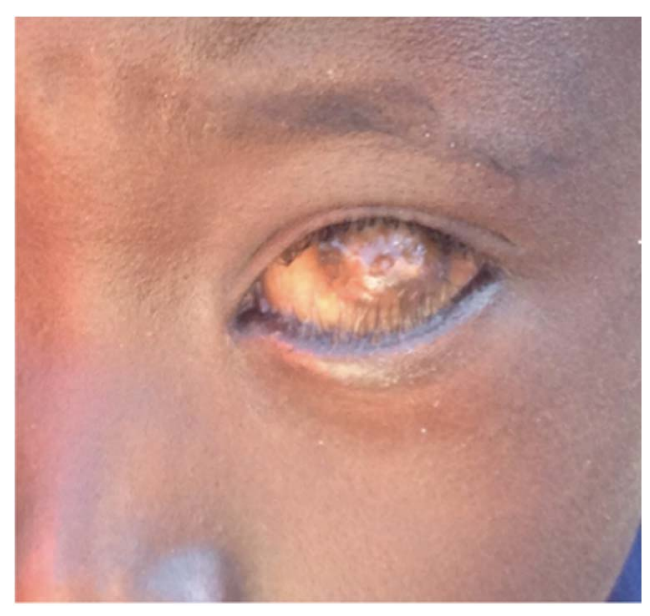

Figure 1. Entropion, trichiasis, and corneal opacity

lashes, Antibiotics, Facial cleanliness, and Environmental improvement. $^{4}$

Competing Interests: None to declare.

\section{REFERENCES}

1. Resnikoff S, Pascolini D, Etya'ale D, et al. Global data on visual impairment in the year 2002. Bull World Health Organ 2004;82(11):844-51.

2. Berhane Y, Worku A, Bejiga A. National Survey on Blindness, Low Vision and Trachoma in Ethiopia. Federal Ministry of Health of Ethiopia; 2006. Available at: http:// pbunion.org/Countriessurveyresults/Ethiopia/Ethiopian_ National_Blindness_and_trachoma_survey.pdf.

3. Solomon AW, Peeling RW, Foster A, et al. Diagnosis and assessment of trachoma. Clin Microbiol Rev 2004;17(4):982-1011.

4. World Health Organization. Trachoma Control: A guide for program managers. Geneva; 2006. Available at: http:// www.trachoma.org/sites/default/files/guidesandmanuals/tcm \%20who_pbd_get_06_1-1.pdf.

From the *Alpert Medical School, Brown University Department of Emergency Medicine, Providence, RI.

Correspondence to: Naomi George, 52 Princeton Avenue, Providence, RI, 02907, USA; Email: nrgeorge@gmail.com 